\title{
Phase Locking to High Frequencies in the Auditory Nerve and Cochlear Nucleus Magnocellularis of the Barn Owl, Tyto alba
}

\author{
Christine Köppl \\ Institut für Zoologie der Technischen Universität München, Lichtenbergstraße 4, 85747 Garching, Germany
}

The auditory system of the barn owl is an important model for temporal processing on a very fast time scale and for the neural mechanisms and circuitry underlying sound localization. Phase locking has been shown to be the behaviorally relevant temporal code. This study examined the quality and intensity dependence of phase locking in single auditory nerve fibers of the barn owl to define the input to the known brainstem circuit for temporal processing. For direct comparison in the same individuals, recordings were also obtained from the relevant next higher center, the nucleus magnocellularis (NM). Phase locking was regularly seen at sound pressure levels (SPL) below those eliciting an increase in spike rate, thus providing an additional cue for signal detection. The quality of phase locking, expressed as vector strength, decreased with increasing frequency. Auditory nerve fibers showed an unusual step-like decline with a prominent plateau in the mid-frequency range $(1.5-3 \mathrm{kHz})$, indicating that some specialization enables the owl to halt the deterioration and extend phase locking to frequencies up to $10 \mathrm{kHz}$, above the range commonly observed in other species. Phase locking in the NM was consistently inferior to that of auditory-nerve fibers at frequencies above $1 \mathrm{kHz}$, suggesting that the synapse plays a limiting role in temporal precision. The response delays, or group delays, derived from the phase-versus-frequency functions of auditory nerve fibers were not consistent with the unusual spatial frequency representation in the owl cochlea. This questions the common assumption that group delays reflect cochlear wave travel times.

Key words: phase locking; auditory nerve; Nucleus magnocellularis; cochlear nucleus; group delay; ITD; bird; owl
Phase locking, i.e., the firing of neurons preferentially at a certain phase of an amplitude-modulated stimulus, is an important general mechanism in sensory physiology. Phase locking encodes the temporal structure of stimuli, from slow modulations to fine structure in the microsecond range in different sensory systems (for example, see Taniguchi and Ogawa, 1987; Surlykke et al., 1988; Heiligenberg, 1989; Wubbels, 1992; Carr, 1993b). The barn owl has become an important model for the study of extremely fast temporal processing based on neural phase locking. The animal uses minute differences in the arrival times of sounds at its two ears to determine the azimuthal location of the sound source (for review, see Konishi, 1993). Auditory nerve fibers encode the ongoing temporal properties of the stimulus through phase locking to its sinusoidal components within individual narrowly tuned ranges of frequencies. A dedicated brainstem circuit then relays the inputs from both auditory nerves via axonal delay lines created by the Nucleus magnocellularis (NM) to neurons of the Nucleus laminaris, which perform binaural coincidence detection (for review, see Carr, 1993a). Although this circuit is in principle well established, very little is known about the phase-locking properties of auditory nerve fibers in the barn owl (Sullivan and Konishi, 1984). The present study was undertaken to fill this significant gap and thus help establish the contributions of the auditory nerve to

\footnotetext{
Received Dec. 4, 1996; revised Jan. 27, 1997; accepted Feb. 14, 1997.

This work was supported by the Deutsche Forschungsgemeinschaft within the SFB 204 "Gehör" and by a fellowship to C.K. Catherine Carr and Otto Gleich kindly provided data from published figures. Georg Klump, Martin Baumann, and Stephan Kießlich were responsible for the excellent custom software and hardware used in the experiments. Geoff Manley and Alex Kaiser made helpful comments on an earlier version of this manuscript.

Correspondence should be sent to Dr. Christine Köppl, Institut für Zoologie der Technischen Universität München, Lichtenbergstraße 4, 85747 Garching, Germany. Copyright (C) 1997 Society for Neuroscience 0270-6474/97/173312-10\$05.00/0
}

the temporal processing task. One important question relates to the putative improvement in the quality of phase locking in the NM over the auditory nerve input. Although phase locking in the owl NM has been studied previously (Sullivan and Konishi, 1984; Carr and Konishi, 1990), data were also recorded in the NM to compare both neuronal populations in the same individual owls.

A second important aspect of the present study was the use of auditory nerve phase locking as a window on cochlear mechanisms of stimulus transduction and encoding. Group delays derived from the response phases of individual auditory nerve fibers contain a frequency-dependent component that increases from high to low frequency fibers. In mammals, this has traditionally been interpreted as reflecting the travel times of the basilar membrane traveling wave to the places of different characteristic frequency (CF) along the cochlea (for review, see Ruggero, 1992). However, quantitatively similar group delays have been found in nonmammalian species having very different inner ear dimensions and morphology (Hillery and Narins, 1984; Gleich and Narins, 1988; for review, see Smolders and Klinke, 1986; Manley et al., 1990). The barn owl offers a unique opportunity to test whether the frequency-dependent component of the group delay indeed reflects travel time over a fixed spatial distance. Frequency representation along the basilar papilla of the barn owl is very unusual, in that the length of epithelium devoted to one octave increases rapidly toward higher frequencies, and the highest octave, 5-10 $\mathrm{kHz}$, occupies more than half of the papillar length (an "auditory fovea”; Köppl et al., 1993). If group delays are related to travel times over distance along the papilla, such an expanded frequency representation should be reflected in the pattern of delays, e.g., in an unusually fast increase in delay from 10 to $5 \mathrm{kHz}$. 


\section{MATERIALS AND METHODS}

Experiments were performed on nine adult barn owls (Tyto alba guttata, five females and four males) from the breeding colony of the Zoology Department at the Technical University of Munich, aged 6 months to 3 years, and weighing between 285 and $390 \mathrm{gm}$. The care and use of these animals was approved by the government of Upper Bavaria (license \#211-2531-64/92). Most of the data reported here were obtained in the same experiments that were described in Köppl (1997). Therefore, the general methods used for anesthesia, surgery, sound stimulation, and single-unit recording will only be briefly repeated, with details only for the methods specific to the present study.

Anesthesia and surgery. General anesthesia was induced and maintained by intramuscular injections of $3 \mathrm{mg} / \mathrm{kg}$ xylazine (rompun) and $4 \mathrm{mg} / \mathrm{kg}$ ketamine hydrochloride (Ketavet), with occasional additional doses of diazepam (Valium, $0.8 \mathrm{mg} / \mathrm{kg}$ ). A combined EKG and muscle potential recording was used to monitor the depth of anesthesia. Rectal temperature was kept at $39-40^{\circ} \mathrm{C}$ with the aid of a heating pad wrapped around the body of the owl. A metal pin was glued to the skull to hold the head securely. The bone and meninges overlying the right cerebellum were removed, and the posterior part of the right cerebellum was aspirated to expose the surface of the auditory brainstem on that side.

Acoustic stimulation. During recordings, the animals were situated in a sound-attenuating chamber. Miniature commercial earphones were coupled to both ears via plastic exponential horns inserted into the ear canals and sealed by soft rubber rings. Sound pressure levels within the ear canals were calibrated for each individual with a miniature microphone, about $10 \mathrm{~mm}$ from the eardrum. In later experiments, the phase of the microphone signal was also calibrated individually with reference to the zero-crossing of the electrical signal (used as the reference for phase recordings, see below). Sound stimuli were generated alternatively by a frequency synthesizer, a white noise source, or a $0.1 \mathrm{msec}$ square wave trigger signal (for click stimuli). Continuous stimuli passed an equalizer and could then be gated by a cosine switch or, for continuous stimulation, bypass the gate. They could also be variably attenuated.

Recordings of cell activity. Glass microelectrodes, filled with $3 \mathrm{M} \mathrm{KCl}$ or $2 \mathrm{M} \mathrm{NaCl}$ and with impedances mostly between 50 and $100 \mathrm{M} \Omega$, were positioned under visual control above the surface of the brainstem and then remotely advanced. Recording signals from a WPI 767 electrometer were mostly high-pass filtered $(300 \mathrm{~Hz}$ cutoff frequency) to eliminate slow baseline fluctuations, and action potentials were fed via a threshold discriminator to a custom-built computer interface. The single-unit nature of all recordings was verified. A variable proportion of recordings, depending on the electrode used, were intracellular, as judged by a sudden negative change of the DC potential coincident with the appearance of spikes. After isolating a unit, the response to ipsilateral condensation clicks was usually recorded first. This was followed by the presentation of a frequency intensity raster of tone bursts at minimally 10 frequencies around the characteristic frequency (CF) of the cell and typically 18 sound pressure levels from below threshold to maximal pressure. These raster data were used later to calculate frequency threshold curves. To investigate phase locking, continuous tones at selected frequencies and sound pressures were then presented until, for each stimulus, 500 spikes had been registered. For most units, a series of frequencies across their response area could be tested at a fixed sound pressure level (between 60 and $90 \mathrm{~dB}$ SPL in different experiments). If time allowed, different sound pressure levels were then tested, beginning with frequencies around CF.

Data analysis. Spontaneous discharge rates and frequency threshold curves were derived from raster data by using different time windows (relative to the stimulus) for counting the spikes. Click latencies were defined as the earliest response bin in poststimulus time histograms, using a bin width of 0.05 msec.

In phase recordings, the timing of every spike relative to the zerocrossing of the electrical frequency signal was recorded with a temporal resolution of $5 \mu \mathrm{sec}$. Period histograms could then be derived from these data, as well as the mean phase relation between the reference signal and the spikes, and the vector strength, both as defined by Goldberg and Brown (1969). Rayleigh's test was applied to evaluate the statistical significance of the vector strength, using $p \leq 0.01$ as the criterion value, which corresponds to a vector strength of 0.1 for 500 recorded spikes. In experiments where an individual phase calibration of the sound system had been obtained, the mean response phases were corrected accordingly. Because the phase calibrations gave virtually identical readings for three successive experiments, the same calibration values were also used to correct mean phases from one previous experiment carried out using the identical setup, but where an individual phase calibration had not been obtained. The corrected values were plotted across frequency for each unit and, assuming a continuous phase roll-off from the lowest to the highest frequencies tested, $360^{\circ}$ were added after each zero-crossing. The resulting values were thus relative, cumulative phase angles within the restricted range of frequencies, for which each individual unit could be tested. Linear regressions were then calculated for these phase-versusfrequency plots, the slopes (in radians) of which were converted into temporal delay, according to the formula

$$
\text { delay }=\frac{\text { slope }}{2 \pi} .
$$

Only functions with minimally 4 data points were used.

\section{RESULTS}

A total number of 202 units was tested for phase-locked responses. Of these, 158 were auditory nerve fibers with CFs between 0.35 and $9 \mathrm{kHz}$, and 44 were NM units with CFs between 0.54 and $7.2 \mathrm{kHz}$. Because the primary target for recordings was the auditory nerve, NM fibers and cells were mostly encountered in their area of overlap with the auditory nerve (Köppl and Carr, 1997), which biased the NM sample toward frequencies below 5 $\mathrm{kHz}$. Unit classification was based on click response latency and on spontaneous discharge rate, as described in detail in Köppl (1997). Auditory nerve fibers were characterized by a combination of short click latency, mostly below $1.5 \mathrm{msec}$, and relatively low spontaneous rate, generally below 150 spikes/sec. NM units had both longer click latencies and higher spontaneous rates.

All auditory nerve fibers and NM units tested showed phaselocked responses to frequencies at least as high as their $\mathrm{CF}$ and commonly beyond it. An example of phase locking in a highfrequency auditory nerve fiber is shown in Figure 1.

\section{Thresholds of phase locking}

Phase locking, i.e., statistically significant vector strengths, was regularly observed even at sound pressure levels below those eliciting the criterion rate increase. However, toward the highest frequencies, an increasing proportion of auditory nerve fibers did not phase lock below their rate threshold or, occasionally, even at levels far above the rate threshold. To obtain an estimate of average phase locking thresholds across frequency, the median difference to the rate threshold of all stimuli that did not elicit significant phase locking was calculated in $1 \mathrm{kHz}$ bins (Fig. 2). These values indicate that, as a population, auditory nerve fibers began to phase lock $10-15 \mathrm{~dB}$ below their rate thresholds at frequencies up to about $6 \mathrm{kHz}$. Above $6 \mathrm{kHz}$, relative phaselocking thresholds increased, being approximately equal to the rate thresholds at $8 \mathrm{kHz}$ and above those at the highest frequencies. It should be emphasized, however, that even at $9-10 \mathrm{kHz}$, the majority of stimuli elicited significant phase locking, in some fibers at levels below rate threshold.

In NM units, phase locking below $6 \mathrm{kHz}$ similarly began $10-15$ $\mathrm{dB}$ below the rate thresholds. At higher frequencies, phase locking thresholds also seemed to increase; however, few data were obtained at those frequencies.

\section{Growth of vector strength with sound pressure level}

Phase-locking quality was expressed as vector strength (Goldberg and Brown, 1969), with values between 0 (homogenous distribution of spikes across the stimulus period) and 1 (perfect synchronization with all spikes occurring at the same stimulus phase). Although phase locking often began below rate threshold, its quality improved with increasing sound pressure level. Individual units varied in the rate at which their vector strength increased, 

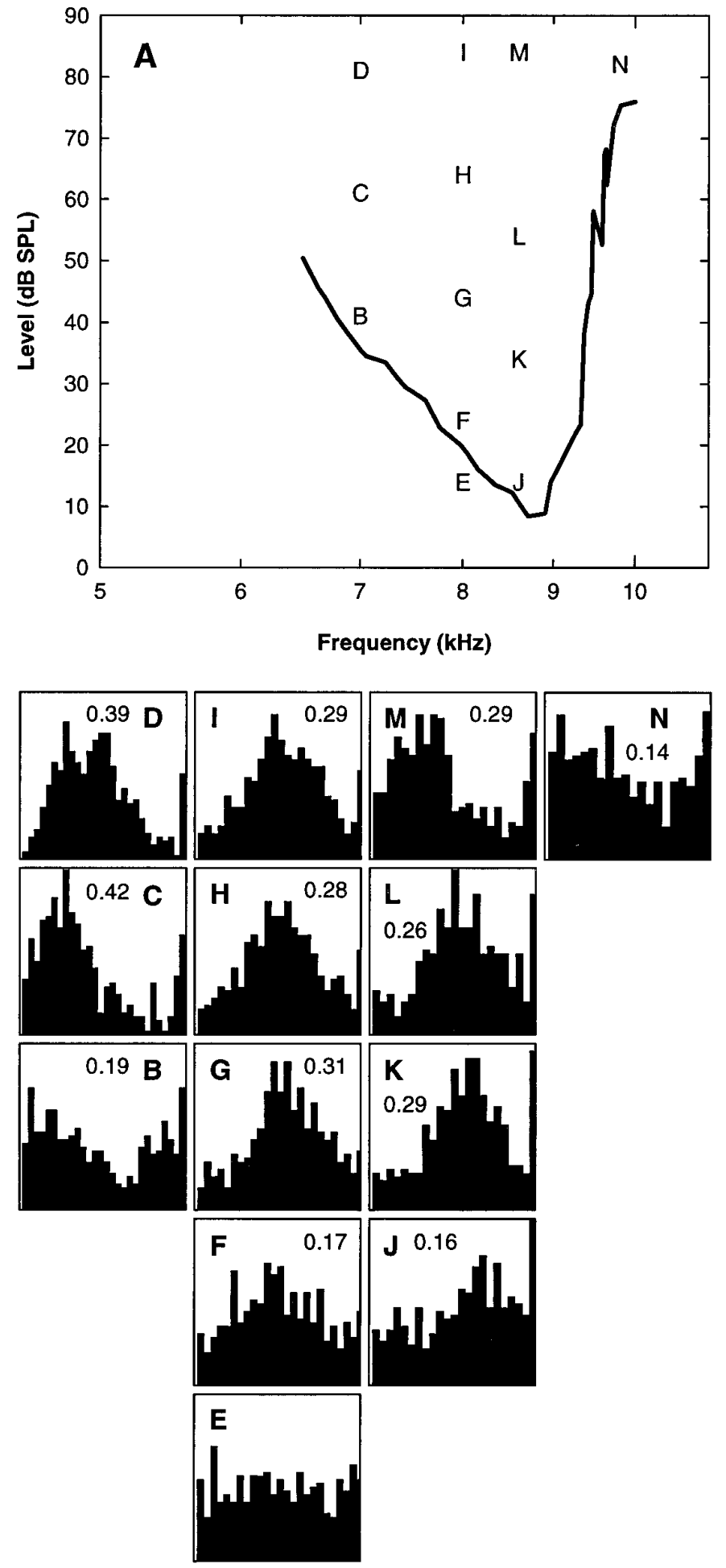

Figure 1. Example of phase locking in an auditory nerve fiber at frequencies near the upper end of the frequency range over which the owl is sensitive. $A$, Rate threshold tuning curve of the fiber; the $\mathrm{CF}$ was $8.7 \mathrm{kHz}$. The positions of the letters $B-N$ indicate the frequencies and levels of stimuli whose corresponding phase histograms are shown in panels $B-N$. Phase histograms showing the number of spikes (ordinates, all scaled identically) that occurred in different time bins relative to the zerocrossing of the sinusoidal stimulus; each histogram covers one stimulus period along the abscissa. All stimuli (except the subthreshold one in $E$ ) produced statistically significant phase locking; the vector strength is given in each panel.

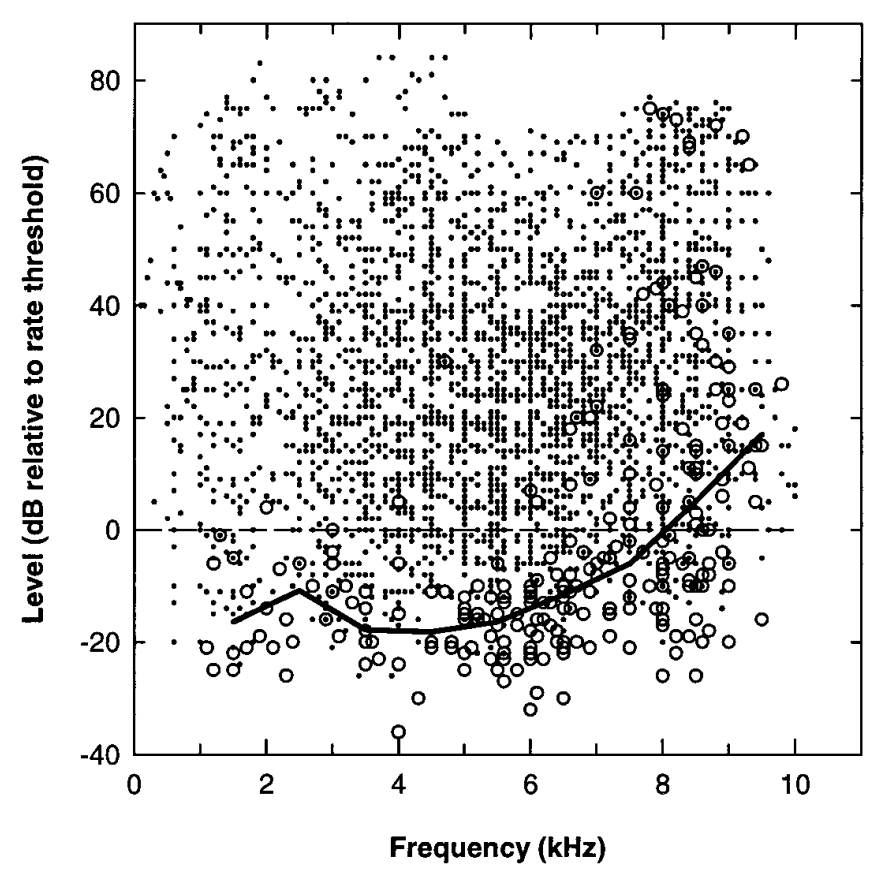

Figure 2. Frequency and relative level above rate threshold of all stimuli tested for phase locking in all auditory nerve fibers. Stimuli that elicited significant phase locking are shown as dots $(n=3115)$, those that failed to elicit phase locking as open circles $(n=254)$. The thin dashed line indicates the rate threshold level. As a measure for phase-locking thresholds as a function of frequency, the median relative levels of all stimuli (in 1 kHz-bins) that did not result in phase locking are connected by the thick solid line. Note that the phase-locking threshold lies $15-20 \mathrm{~dB}$ below the rate threshold up to $6 \mathrm{kHz}$, but approaches the rate threshold and even lies above it toward the upper end of the frequency range of the owl.

reaching a plateau of vector strength somewhere between near rate threshold and about $20 \mathrm{~dB}$ above it. Several examples of units of different $\mathrm{CF}$ are shown in Figure 3. At $20 \mathrm{~dB}$ above rate threshold, maximal vector strength was generally achieved. Auditory nerve fibers (Fig. 3A-C) and NM units (Fig. 3D-F) did not seem to differ in this respect.

\section{Maximal vector strengths and temporal dispersion across frequencies}

To reveal the upper limit of phase-locking quality in the barn owl, only statistically significant vector strength values obtained with stimuli at least $20 \mathrm{~dB}$ above the respective rate threshold were plotted (Fig. 4). In both auditory nerve fibers and NM units, vector strengths at the lowest frequencies tested $(0.2-0.4 \mathrm{kHz})$ were degraded because of double spiking evident as two closely spaced peaks in the phase histogram (peak splitting). This phenomenon ceased above $0.4-0.5 \mathrm{kHz}$, where the highest vector strengths, around 0.9 , were observed. In auditory nerve fibers, vector strength then showed a decline between $1 \mathrm{kHz}$ and $1.6 \mathrm{kHz}$, followed by a prominent plateau at a vector strength value around 0.68 (Fig. 4A). Above 3-4 kHz, vector strength again declined, down to a value of 0.2 at $9 \mathrm{kHz}$. Thus, vector strength in auditory nerve fibers showed a clear step in its decline with increasing frequency. This pattern was identical when the data were restricted to frequencies close to CF (Fig. 4B). Two previously used measures of the cutoff frequency of phase locking, the frequency where vector strength reaches $1 / \sqrt{ } 2$ of its maximal value (Weiss and Rose, 1988a) and 0.5 (Palmer and Russell, 1986), respectively, lay at 3.0 and $5.0 \mathrm{kHz}$, for the barn owl median curve (Fig. 4A). 

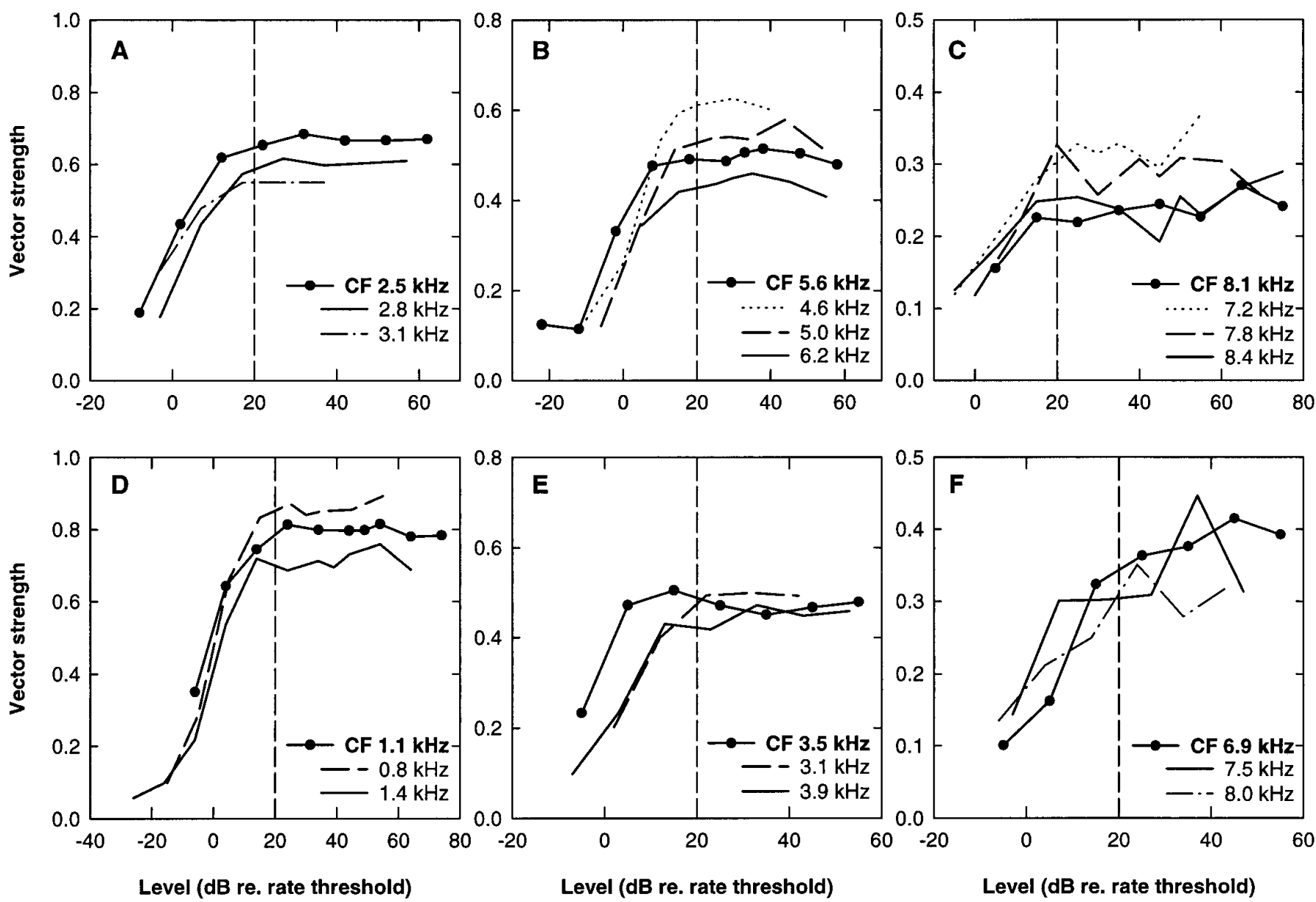

Figure 3. $A-F$, Examples of the growth of vector strength with rising stimulus level in neurons of different CF. $A-C$, Data from auditory nerve fibers; $D-F$, data from NM units. Each panel shows several curves from a single unit at the different stimulus frequencies indicated. Only stimulus levels producing significant phase locking are included. A vertical dashed line in each panel indicates the level above which saturation of vector strength was generally assumed and values were included in Figure 4.

Vector strengths of NM units declined steadily above about 0.8 $\mathrm{kHz}$, without the clear plateau seen in auditory nerve data (Fig. $4 C$ ). Also, NM data generally scattered more. When comparing the two data sets (see also Fig. 12), auditory nerve fibers showed significantly higher vector strengths between 0.9 and $6 \mathrm{kHz}$ (all $p<0.01$; Mann-Whitney $U$ tests in the same quarter octave bins used for calculating the median values shown in Fig. 4).

It should be emphasized that auditory nerve fibers and NM units were recorded in the same individual owls, and were often neighbors in the same electrode tracks. Comparing responses of individual units from the same owl confirmed that the difference between auditory nerve and NM data were genuine, with only rare exceptions, and not an artifact of pooling across animals (Fig. 5). Also, the unusual plateau of vector strength in the midfrequencies was evident in many responses of individual auditory nerve fibers where a suitably large range of frequencies could be tested (Fig. 5A-C).

Phase locking at increasingly higher frequencies requires an increasingly higher temporal precision of the neuron because the stimulus period is steadily decreasing on an absolute time scale. For example, to achieve the same vector strength at $10 \mathrm{kHz}(0.1$ msec period) as at $1 \mathrm{kHz}(1 \mathrm{msec}$ period $)$, the temporal jitter or dispersion of spikes must decrease by one order of magnitude. If the vector strength is known, the temporal dispersion may be calculated from it (Hill et al., 1989), according to:

$$
s=\frac{\sqrt{2(1-r)} \frac{1}{f}}{2 \pi},
$$

where $s=$ temporal dispersion (in seconds), $r=$ vector strength, and $f=$ frequency (in $\mathrm{Hz}$ ). Figure 6 shows the derived values for temporal dispersion. Temporal dispersion was highest, up to 1 msec, at the lowest frequencies tested and fell with increasing frequency, approaching $22 \mu \mathrm{sec}$ at $9-10 \mathrm{kHz}$. The overall decline was well described by a power law. In the auditory nerve data (Fig. $6 A$ ); however, deviations in the $1-3 \mathrm{kHz}$ range mirrored the step-like behavior of vector strength across frequency. Also, corresponding to their higher vector strength over most of the frequency range, auditory nerve fibers showed less temporal dispersion than NM units.

\section{Mean phase angles at different sound pressure levels}

Data on mean response phases at different frequencies and sound pressure levels were obtained from a subset of neurons, 53 auditory nerve fibers and $17 \mathrm{NM}$ units from 3 animals.

Mean response phase at any given frequency changed systematically with sound pressure level. With rising level, the mean 

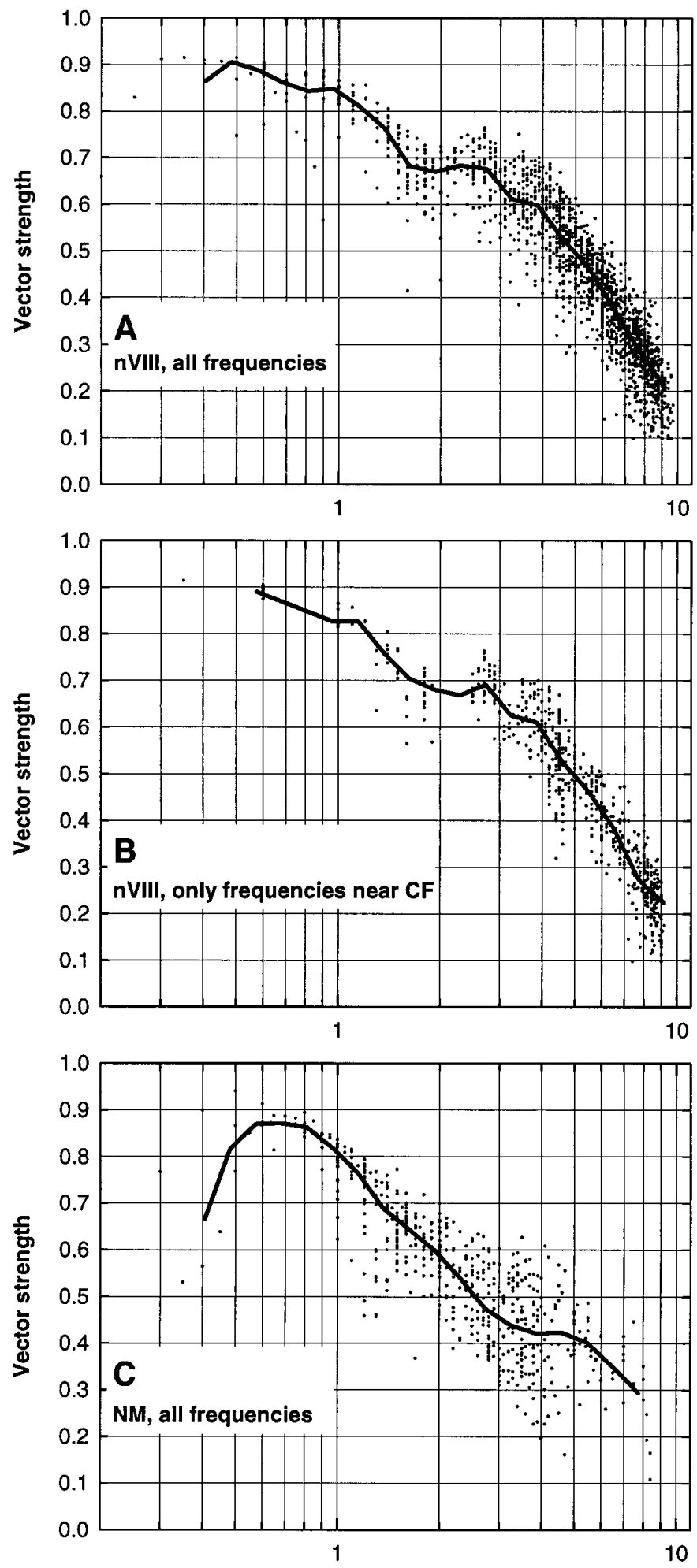

Frequency $(\mathbf{k H z})$

Figure 4. Vector strength as a function of stimulus frequency. Only values for stimuli whose level was at least $20 \mathrm{~dB}$ above the rate threshold, i.e., where vector strength was saturated, are shown. The solid lines connect the median values calculated for quarter octave bins. $A$, All data from auditory nerve fibers $(n=1947)$. $B$, Data from auditory nerve fibers but restricted to stimuli close to $\mathrm{CF}$ (CF \pm 0.1 octaves for CFs up to $5 \mathrm{kHz}$, $\mathrm{CF} \pm 0.05$ octaves for CFs above $5 \mathrm{kHz} ; n=661)$. $C$, All data from NM units $(n=572)$. response phase advanced at frequencies below the $\mathrm{CF}$ of the neuron, and lagged at frequencies above the CF. Near the CF, the mean response phase was almost independent of sound pressure level (examples in Fig. 7). However, the frequency with the most level-independent response phase did not necessarily correspond to the CF (Fig. 7).

For every stimulation frequency at which at least four different sound pressure levels had been tested and produced significant phase locking, a linear regression was calculated, its slope indicating the rate of change in mean response phase as a function of sound pressure level. The rate of change generally increased with increasing distance from the frequency with the most stable response near CF (Fig. 8). Most data fell within a frequency range of \pm 0.2 octaves from the $\mathrm{CF}$, where the mean response phase changed at a rate of up to \pm 5 degrees $/ \mathrm{dB}$ (up to -8.5 degrees $/ \mathrm{dB}$ in some high $\mathrm{CF}$ units). Converted into $\mu \mathrm{sec} / \mathrm{dB}$ (Fig. 8), the maximal values for frequencies 0.2 octaves below and above $\mathrm{CF}$ reached up to $+5.5 \mu \mathrm{sec} / \mathrm{dB}$, but only $-2.5 \mu \mathrm{sec} / \mathrm{dB}$, respectively. Within the frequency range of overlap between the two data sets, i.e., up to $4 \mathrm{kHz}$, auditory nerve fibers and $\mathrm{NM}$ units did not differ in this respect (Mann-Whitney $U$ test).

\section{Response delays at different sound pressure levels}

A constant response delay will result in a linear relationship between frequency and mean response phase angle, the slope of which represents the delay. Such phase-versus-frequency functions for both auditory nerve fibers and NM units were generally well represented by linear regressions.

Because of the systematic shift of mean response phase with sound pressure level at different frequencies (described above), the phase-versus-frequency function of a given neuron tilted with varying sound pressure level (Fig. 7), indicating a change in response delay. With increasing level, the functions became flatter, corresponding to a shorter delay. For 15 auditory nerve fibers and 3 NM units, where phase-versus-frequency functions were obtained at least at 4 different absolute sound pressure levels, the change of response delay with level seemed approximately linear (Fig. 9). Linear regressions indicated a rate of change of delay between -0.009 and $-0.025 \mathrm{msec} / \mathrm{dB}$.

\section{Response delays across frequency}

The response delays calculated from the phase-versus-frequency functions varied systematically with the $\mathrm{CF}$ of the neurons, high CF units having shorter delays than low CF units. Delays obtained with stimulation at two different absolute levels, 80-90 dB SPL and 55-65 dB SPL, respectively, are shown in Figure 10.

The most complete data set is available for the auditory nerve for stimulation at $80-90 \mathrm{~dB}$ SPL, and the data are well represented by a power function with a high frequency asymptote at $0.83 \mathrm{msec}$ (Fig. 10A). Delays of NM units were $0.5-1 \mathrm{msec}$ longer than auditory nerve fibers of the same CF (Fig. 10A,B).

\section{DISCUSSION}

Several aspects of the data reported here, e.g., the relative thresholds of phase locking or the intensity dependence of the mean response phases, are qualitatively similar to data previously described for auditory nerve fibers in other species (Anderson et al., 1971; Johnson, 1980; Kettner et al., 1985; Palmer and Russell, 1986; Smolders and Klinke, 1986; Hillery and Narins, 1987; Gleich and Narins, 1988; Hill et al., 1989; Joris et al., 1994). The quantification provided here will be very useful for future evaluation of the contributions of the different stages of the ascending auditory 

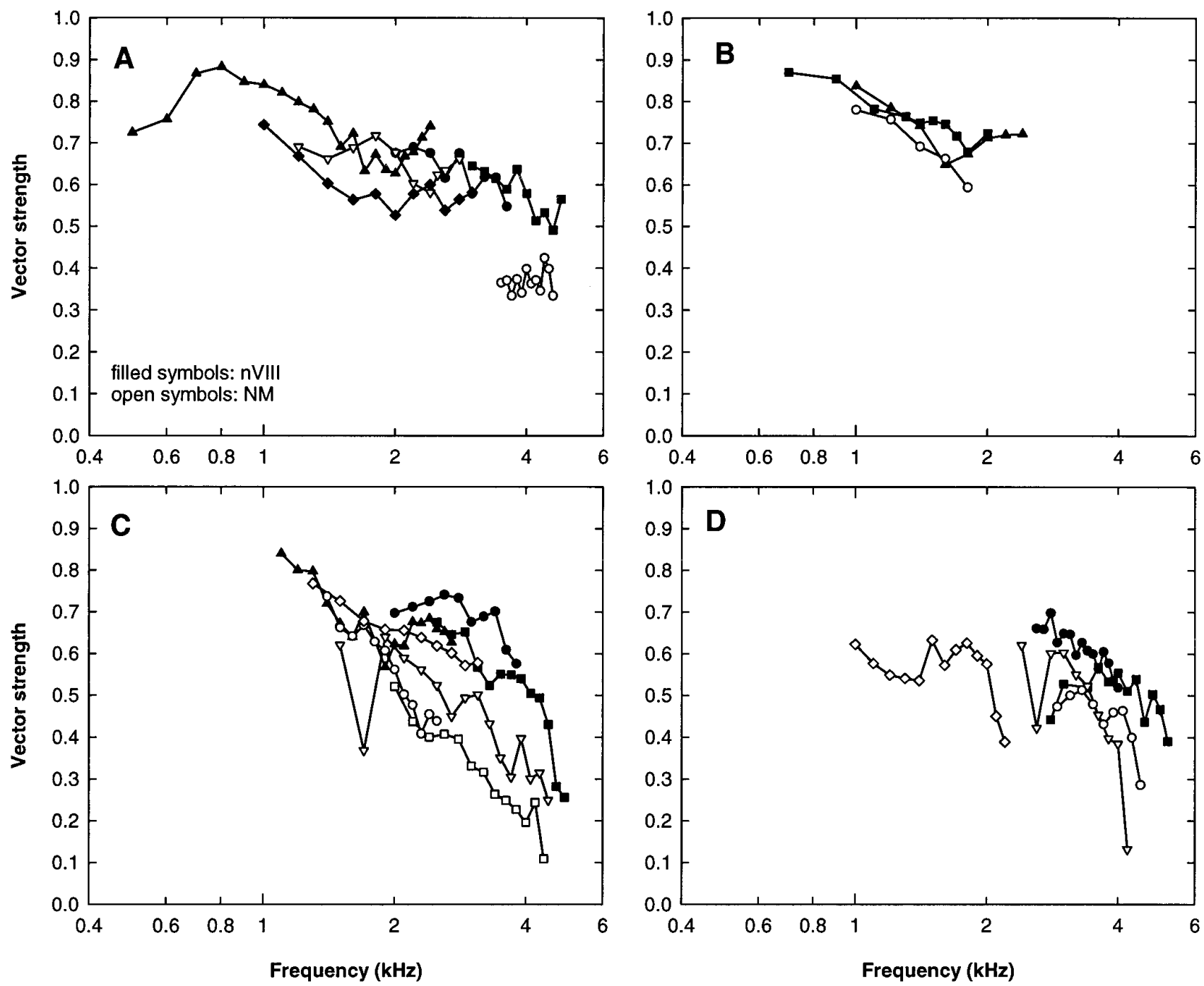

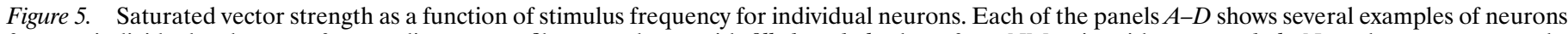

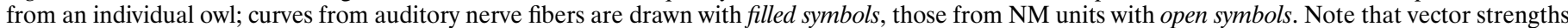

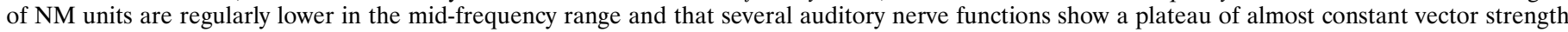
values between 2 and $3 \mathrm{kHz}$.

pathway to temporal processing in the barn owl. The discussion will be limited to three topics to which the barn owl data offer a unique contribution or that pose important questions for future research.

\section{Phase locking up to $\mathbf{1 0} \mathbf{k H z}$ : how is it achieved?}

The most striking feature of phase locking in the barn owl is the ability to maintain it up to frequencies near $10 \mathrm{kHz}$. In this respect, the barn owl exceeds all other species investigated by an octave or more (Sachs et al., 1974, 1980; Johnson, 1980; Sullivan and Konishi, 1984; Kettner et al., 1985; Palmer and Russell, 1986; Hillery and Narins, 1987; Gleich and Narins, 1988; Rose and Weiss, 1988; Hill et al., 1989; Carr and Konishi, 1990; Manley et al., 1990, 1997; Salvi et al., 1992; Joris et al., 1994). Although Teich et al. (1993) claimed phase locking up to $18 \mathrm{kHz}$ in auditory nerve fibers of the cat, this does not change the general conclusion of superior phase locking in the owl. First, Teich et al. (1993) attributed their ability to detect phase locking at the highest frequencies to the use of a peak detection routine for determining spike occurrence, which, in their hands, improved vector strengths at frequencies above $5 \mathrm{kHz}$. In the present study, using conventional level detection of spikes, phase locking was seen up to 10 $\mathrm{kHz}$ in the auditory nerve of the owl. Second, of the five examples shown by Teich et al. (1993) for phase locking above $5 \mathrm{kHz}$, only three reached a vector strength $\geq 0.1$ (our criterion for significant phase locking), even using peak detection.

Figure 11 compares maximal vector strength in auditory nerve data from a range of avian and mammalian species. The obvious differences between species raise the question as to the mechanisms and limiting factors for phase locking in the auditory nerve. Temperature is very likely an important variable, partly explaining the low cutoff frequencies in ectothermic species (Weiss and Rose, 1988a), which were therefore not included in Figure 11. Assuming that the AC component of the receptor potential of the hair cell is driving the phase-locked response in the afferent fiber, the filtering properties of the hair cell membrane and the chemical synapse can also be expected to limit phase locking (Palmer and Russell, 1986; Weiss and Rose, 1988b; Kidd and Weiss, 1990). In the guinea pig (Palmer and Russell, 1986), there is a close 

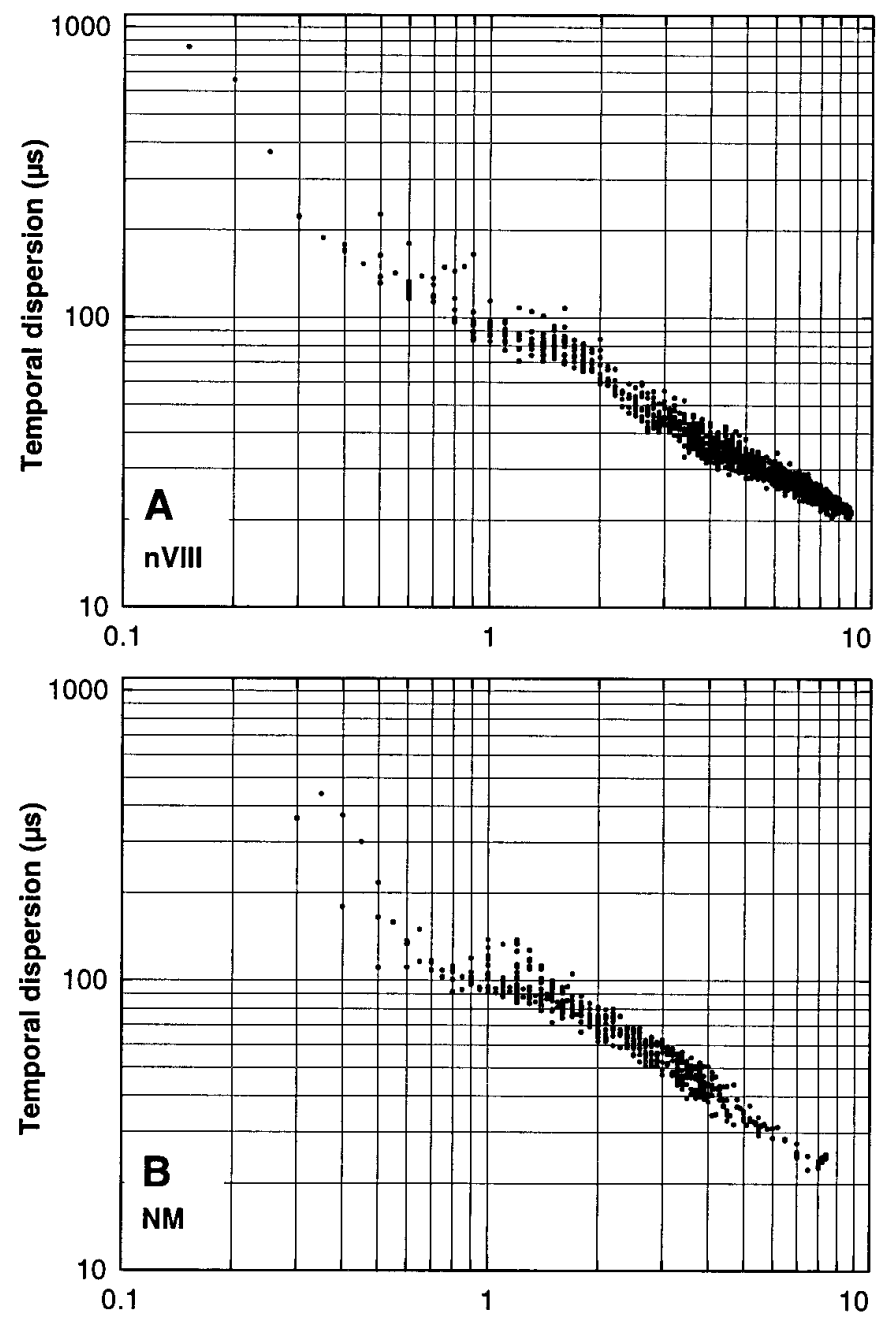

Frequency $(\mathrm{kHz})$

Figure 6. Temporal dispersion as a function of stimulus frequency. Temporal dispersion was derived from the vector strengths shown in Figure 4, $A$ and $C$, respectively (for details see Results) $A$, Data from auditory nerve fibers. $B$, Data from NM units.

correspondence between the decline of neural vector strength and the decline in the $\mathrm{AC} / \mathrm{DC}$ ratio of inner hair cell receptor potentials with increasing frequency, suggesting a limiting influence of the hair cell. Using electrical stimulation of the auditory nerve, that bypasses the hair cell membrane and synapse, the high frequency cutoff of phase locking in auditory nerve fibers can be increased above that seen with acoustic stimulation (Dynes and Delgutte, 1992). On the basis of the observation that even though vector strength deteriorates with increasing frequency, temporal dispersion is reduced, Hill et al. (1989) suggested that even under normal acoustic stimulation, a significant part of the AC potential driving the afferent fiber may be mediated by a mechanism bypassing the hair cell receptor potential and synapse. A specific mechanism has been proposed by Dallos and Evans (1995) in a different context. They suggested that extracellular potential gradients across the hair cells, that would not be filtered by the cell membrane, could be driving high frequency outer hair cell motility in mammals. Might this also be the driving force of high frequency phase locking in the barn owl? One characteristic of the data obtained with extracellular electrical stimulation is the shallow
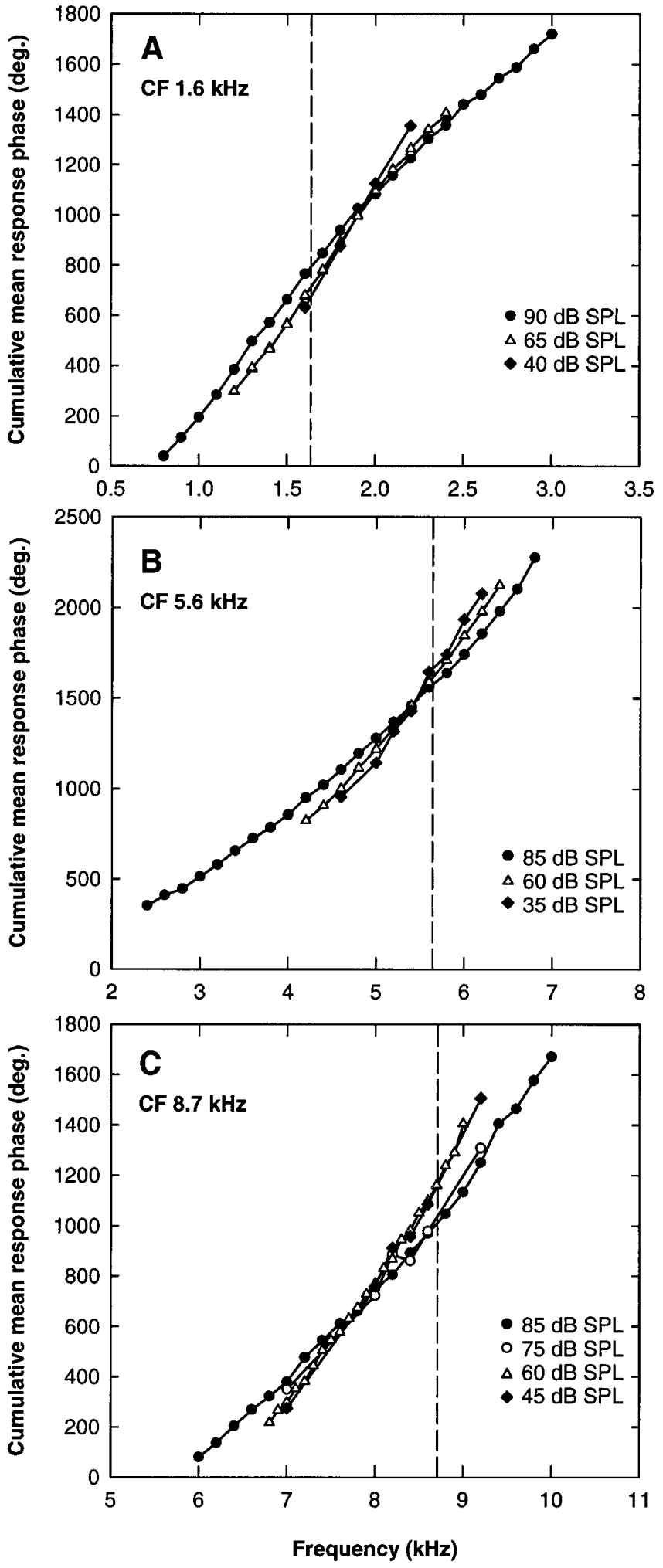

Figure 7. $A-C$, Three examples of the change in phase-versus-frequency functions with changes in sound pressure level. $A$, Curves from a low frequency NM unit. $B, C$, Curves from a mid- and high-frequency auditory nerve fiber, respectively. The cumulative mean response phase is plotted as a function of stimulus frequency. The vertical dashed line in each panel indicates the $\mathrm{CF}$ of the neuron. Note the tilting of the phase-versusfrequency functions around a frequency with the most stable mean response phase, which changes from lying above the $\mathrm{CF}$ in the low $\mathrm{CF}$ neuron $(A)$ to below the $\mathrm{CF}$ in the high $\mathrm{CF}$ neuron $(C)$. 


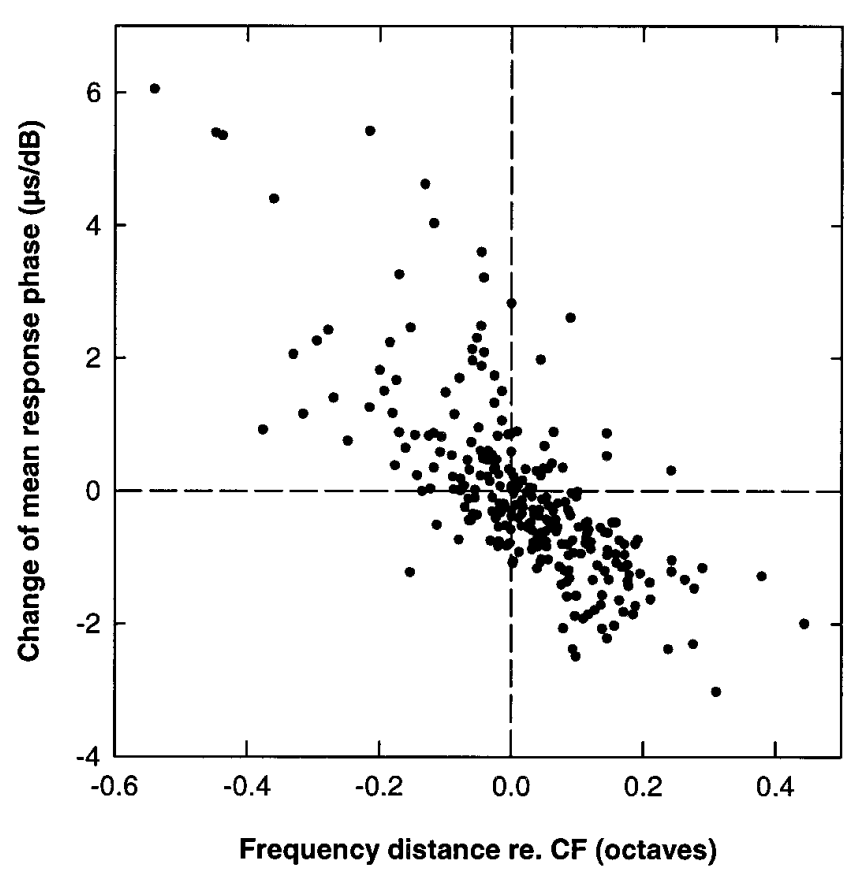

Figure 8. The rate of change of the mean response phase with level, as a function of the distance of the stimulus frequency from the respective CF. Only data from auditory nerve fibers are shown $(n=265)$.

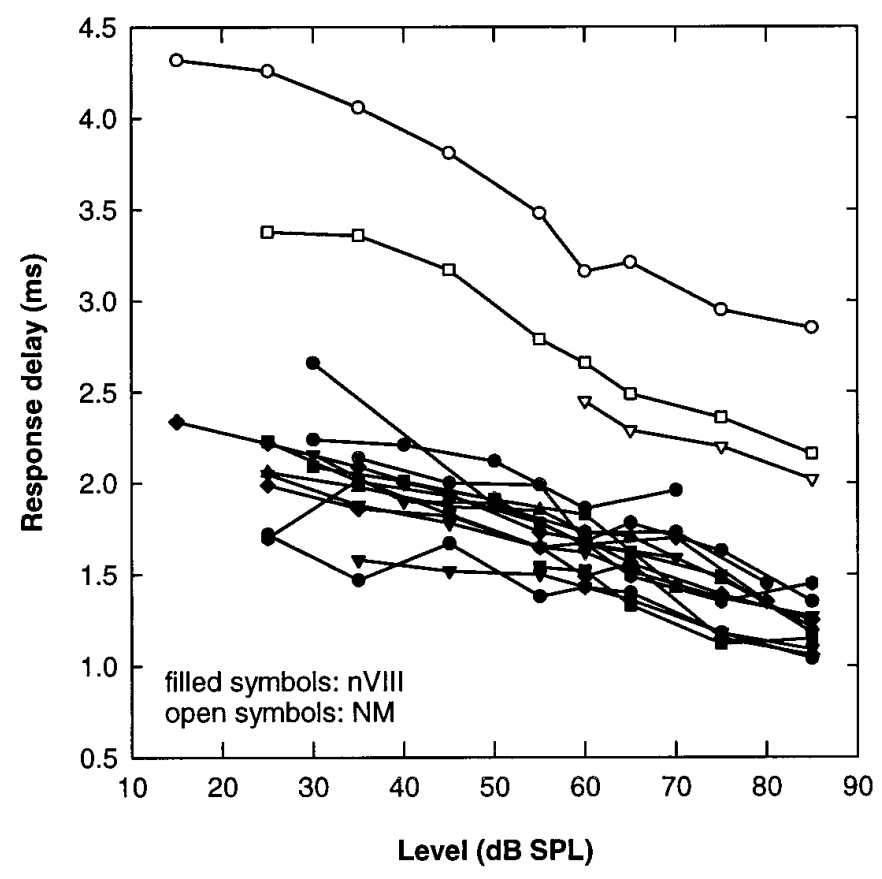

Figure 9. The response delay (derived from the slope of the phaseversus-frequency function, see Materials and Methods) as a function of stimulus sound pressure level. The lines connect data from individual neurons; those from auditory nerve fibers are drawn with filled symbols, those from NM units with open symbols. Note that the response delay decreases approximately linearly with rising sound pressure level.

and gradual decline of vector strength at high frequencies. In contrast to this, the auditory nerve data of the owl showed a steep final decline above $4 \mathrm{kHz}$, the slope of which appeared similar to that of other acoustic data (Fig. 11). The step-like decline of vector strength with frequency in the owl may indicate that specializations restricted to the high frequency hair cells and their
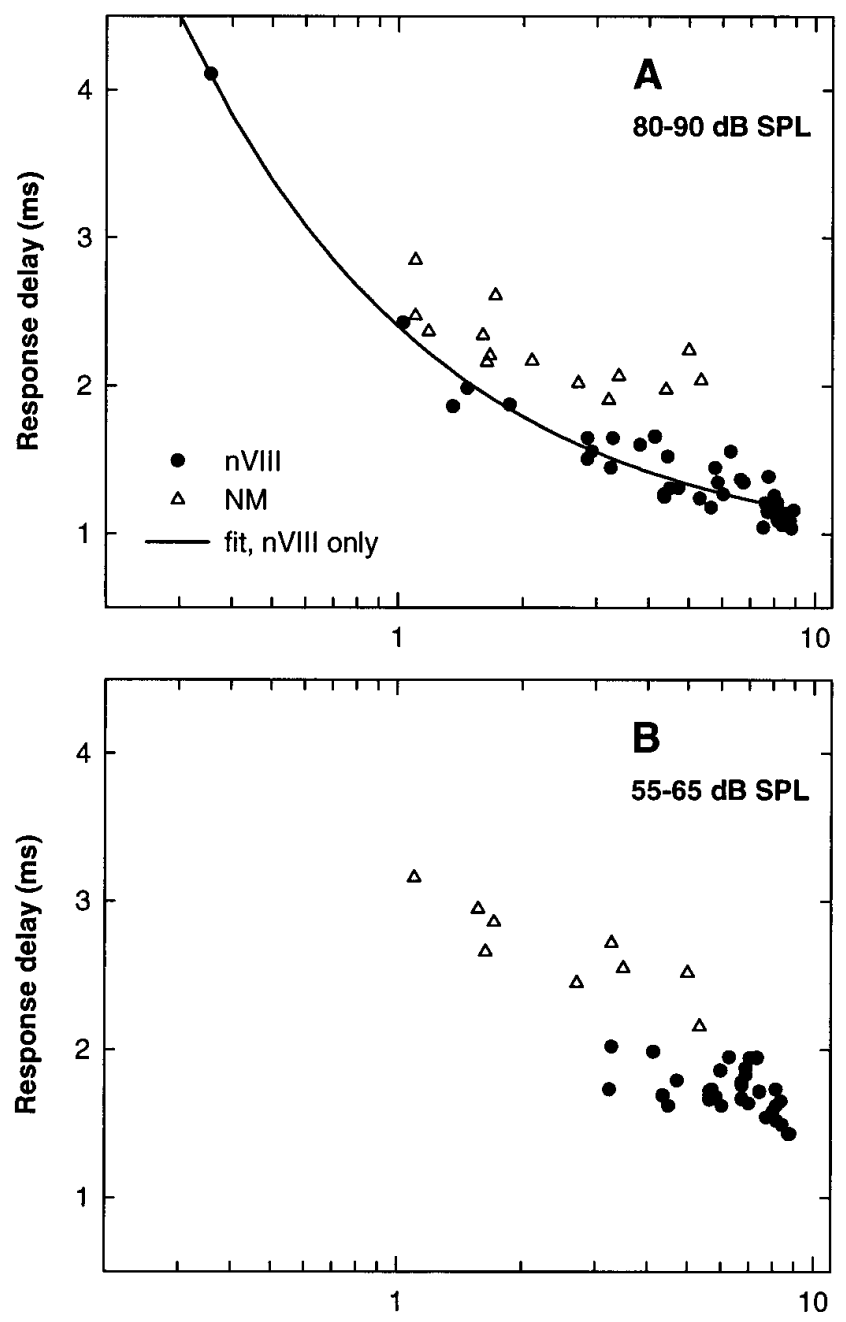

Characteristic frequency $(\mathrm{kHz})$

Figure 10. The response delay as a function of CF. Data from auditory nerve fibers are drawn as filled circles, those from NM units as open triangles. A, Delays derived from phase-versus-frequency functions obtained at $80-90 \mathrm{~dB}$ SPL stimulus level. The solid line shows the power fit to the auditory nerve data only $\left(\right.$ delay $=205 C F(\text { in } \mathrm{Hz})^{-0.706}+0.833 ; n=$ $40) . B$, Delays derived from data obtained with a lower stimulus level of $55-65 \mathrm{~dB}$ SPL.

afferents enabled an extension of the phase-locking range. Investigation of the receptor potentials and membrane channel properties of hair cells in the basal high frequency regions of the barn owl cochlea would be highly interesting in this context.

\section{Does phase locking improve in the cochlear nucleus?}

In the present study, vector strengths above about $1 \mathrm{kHz}$ were consistently higher in the auditory nerve than in NM. This is in contrast to the results of Sullivan and Konishi (1984), who found nearly reverse values and concluded that phase locking was improved in the NM. However, their auditory nerve sample was small (37 units) and the recordings were made in the vicinity of nucleus angularis, that was shown not to phase lock very well at high frequencies. Using spike waveform and spatial coordinates to distinguish between auditory nerve fibers and NA units, some recordings, e.g., from fibers leaving NA, might have been wrongly classified, leading to apparently low vector strengths in the auditory nerve data. It still remains unclear why the vector strengths of 


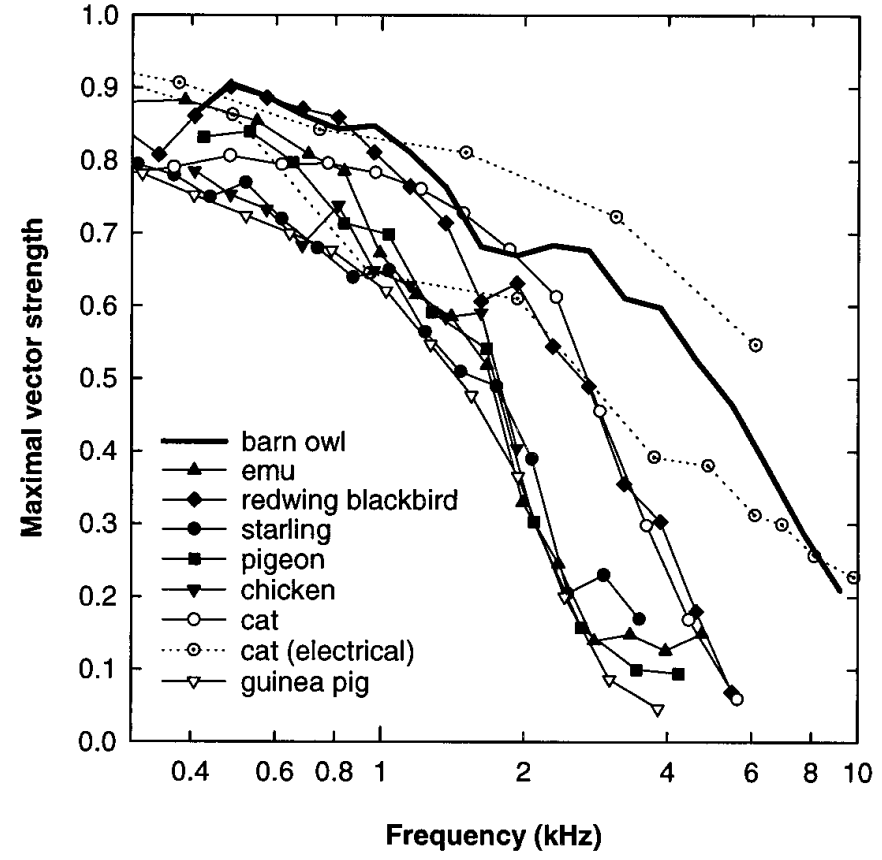

Figure 11. A comparison of maximal vector strength as a function of frequency in the auditory nerve of several avian and mammalian species. For the bird species, median values in mostly quarter octave bins are shown, taken or calculated from the following sources: barn owl, data from Figure 4A; emu, Figure 9 in Manley et al. (1997); redwing blackbird, Figure 11-9B in Sachs et al. (1980); starling, Figure 4 in Gleich and Narins (1988); pigeon, graphic estimate of median values from Figure 2 in Hill et al. (1989); chicken, Figure 16 from Salvi et al. (1992). For the cat and guinea pig, average values in 0.1 decade bins as determined by Weiss and Rose (1988a, their Fig. 3) from the original data (Johnson, 1980; Palmer and Russell, 1986) are shown. The two different data sets for electrical stimulation in the cat (Hartmann and Klinke, 1987; Dynes and Delgutte, 1992) are mean values taken from Figure 10 in Dynes and Delgutte (1992).

the present NM sample were lower than those reported by Sullivan and Konishi (1984) at the same frequencies; however, my NM data agree with those subsequently measured by Carr and Konishi (1990) and Peña et al. (personal communication). Comparing all published sets of barn owl NM data to the median curve for the auditory nerve (Fig. 12), it is concluded that phase locking at high frequencies definitely does not improve in the NM, but rather that phase locking in the NM is inferior to that of the auditory nerve.

A decrease of vector strength at high frequencies between the auditory nerve and the NM is also seen in the chicken (Warchol and Dallos, 1990; Salvi et al., 1992) and between the auditory nerve and the anteroventral cochlear nucleus (AVCN) in the cat (Joris et al., 1994). A deterioration of phase-locking quality at high frequencies is thus consistently seen in different species, in spite of specializations in synaptic morphology and membrane channel properties thought to optimize temporal responses in the NM and AVCN, respectively (Hackett et al., 1982; Oertel, 1985; Cant, 1992; Carr, 1992; Raman and Trussell, 1992). This may reflect an irreducible amount of temporal jitter at the synapses. Although theoretically, convergence of inputs and mandatory coincidence could provide compensation for such jitter (Joris et al., 1994), a convergence of only 2-3 auditory nerve fiber inputs has been estimated in both NM neurons and the spherical bushy cells in the AVCN, at least at high frequencies (Carr and Boudreau, 1991; Liberman, 1991). Also, the high spontaneous rates of these neurons (for example, see Smith et al., 1993; Köppl, 1997)

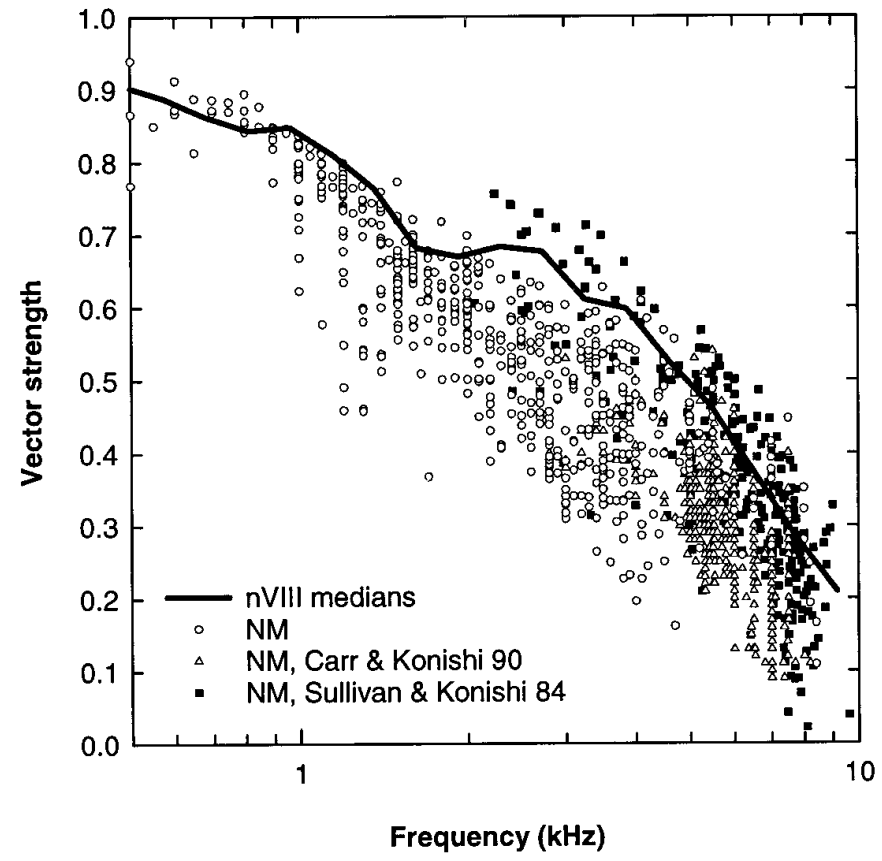

Figure 12. A comparison of saturated vector strength as a function of frequency, as determined by different investigators in the auditory nerve and NM of the barn owl. The thick line represents median values for the auditory nerve as shown in Figure $4 A$. Open circles repeat the NM data shown in Figure $4 C$. Open triangles are NM data shown in Figure $5 D$ of Carr and Konishi (1990). Filled squares are the NM data shown in Figure 2 of Sullivan and Konishi (1984). Note that the majority of NM data lies below the median curve for the auditory nerve data.

and the characteristic prepotential to each spike in spherical bushy cells (for example, see Rhode and Greenberg, 1992) indicate that single auditory nerve spikes can induce a postsynaptic spike and thus that coincidence is not required.

\section{Group delays, traveling waves, and the auditory fovea in the barn owl}

The response delays derived from the linear approximations of phase-versus-frequency functions of cochlear afferents, commonly called group delays, include several different delays, introduced at successive stages of stimulus processing. Most of these are assumed to be independent of frequency, e.g., delays caused by the middle ear, synaptic transmission and neural conduction to the recording site. However, group delays also include a frequencydependent component that is commonly assumed to reflect the travel times of a traveling wave (either in the basilar or tectorial membrane) to the places of different CF along the cochlea (Hillery and Narins, 1984, 1987; Ruggero, 1992). The barn owl shows a very uneven spatial representation of frequencies along its cochlea, with an auditory fovea for the behaviorally very important range of 3-10 kHz (Köppl et al., 1993). However, no reflection of this spatial over-representation was seen in the group delays. Rather they were similar, both in their absolute values and in their power law dependence on $\mathrm{CF}$, to data from a variety of other vertebrate species (Hillery and Narins, 1984; Gleich and Narins, 1988; for review, see Smolders and Klinke, 1986; Manley et al., 1990). To explain the barn owl data in terms of a traveling wave, it would have to be assumed that the average wave velocity first increases from the basal, high frequency end into the auditory fovea before it decreases toward the low frequency apical end. I believe a more general interpretation is appropriate, as suggested 
by Smolders and Klinke (1986). Group delays reflect differential response times of cochlear filters with different center frequencies, as opposed to travel times over fixed spatial distances. A basilar membrane traveling wave may still be the result of such filters, as direct measurements in the pigeon suggest (Gummer et al., 1987).

\section{REFERENCES}

Anderson DJ, Rose JE, Hind JE, Brugge JF (1971) Temporal position of discharges in single auditory nerve fibres within the cycle of a sine-wave stimulus: frequency and intensity effects. J Acoust Soc Am 49:1131-1139.

Cant NB (1992) The cochlear nucleus: neuronal types and their synaptic organization. In: The mammalian auditory pathway: neuroanatomy (Webster DB, Popper AN, Fay RR, eds), pp 66-116. New York: Springer.

Carr CE (1992) Evolution of the central auditory system in reptiles and birds. In: The evolutionary biology of hearing, Ed 1 (Webster DB, Fay RR, Popper AN, eds), pp 511-543. New York: Springer.

Carr CE (1993a) Delay line models of sound localization in the barn owl. Am Zool 33:79-85.

Carr CE (1993b) Processing of temporal information in the brain. Annu Rev Neurosci 16:223-243.

Carr CE, Boudreau RE (1991) Central projections of auditory nerve fibers in the barn owl. J Comp Neurol 314:306-318.

Carr CE, Konishi M (1990) A circuit for detection of interaural time differences in the brain stem of the barn owl. J Neurosci 10:3227-3246.

Dallos P, Evans BN (1995) High-frequency motility of outer hair cells and the cochlear amplifier. Science 267:2006-2009.

Dynes SBC, Delgutte B (1992) Phase-locking of auditory-nerve discharges to sinusoidal electric stimulation of the cochlea. Hear Res 58:79-90.

Gleich O, Narins PM (1988) The phase response of primary auditory afferents in a songbird (Sturnus vulgaris L.). Hear Res 32:81-92.

Goldberg JM, Brown PB (1969) Response of binaural neurons of dog superior olivary complex to dichotic tonal stimuli: some physiological mechanisms of sound localization. J Neurophysiol 32:613-636.

Gummer AW, Smolders JWT, Klinke R (1987) Basilar membrane motion in the pigeon measured with the Mössbauer technique. Hear Res 29:63-92.

Hackett JT, Jackson H, Rubel EW (1982) Synaptic excitation of the second and third order auditory neurons in the avian brain stem. Neuroscience 7:1455-1469.

Hartmann R, Klinke R (1987) Impulse pattern in auditory-nerve fibres to extra- and intra-cochlear electrical stimulation. In: Cochlear implants: current situation (Banfai P, ed), pp 73-86. Düren, Germany: International Cochlear Implant Symposium.

Heiligenberg W (1989) Coding and processing of electrosensory information in gymnotiform fish. J Exp Biol 146:255-275.

Hill KG, Stange G, Mo J (1989) Temporal synchronization in the primary auditory response in the pigeon. Hear Res 39:63-74.

Hillery CM, Narins PM (1984) Neurophysiological evidence for a travelling wave in the amphibian inner ear. Science 225:1037-1039.

Hillery CM, Narins PM (1987) Frequency and time domain comparison of low-frequency auditory fiber responses in two anuran amphibians. Hear Res 25:233-248.

Johnson DH (1980) The relationship between spike rate and synchrony in responses of auditory-nerve fibers to single tones. J Acoust Soc Am 68:1115-1122.

Joris PX, Carney LH, Smith PH, Yin TCT (1994) Enhancement of neural synchronization in the anteroventral cochlear nucleus. I. Responses to tones at the characteristic frequency. J Neurophysiol 71:1022-1036.

Kettner RE, Feng J-Z, Brugge JF (1985) Postnatal development of the phase-locked response to low frequency tones of auditory nerve fibers in the cat. J Neurosci 5:275-283.

Kidd RC, Weiss TF (1990) Mechanisms that degrade timing information in the cochlea. Hear Res 49:181-208.

Köppl C (1997) Frequency tuning and spontaneous activity in the auditory nerve and cochlear nucleus magnocellularis of the barn owl Tyto alba. J Neurophysiol 77:364-377.

Köppl C, Carr CE (1997) A low-frequency pathway in the barn owl's auditory brainstem. J Comp Neurol 378:265-282.
Köppl C, Gleich O, Manley GA (1993) An auditory fovea in the barn owl cochlea. J Comp Physiol [A] 171:695-704.

Konishi M (1993) Listening with two ears. Sci Am 268:66-73.

Liberman MC (1991) Central projections of auditory-nerve fibers of differing spontaneous rate. I. Anteroventral cochlear nucleus. J Comp Neurol 313:240-258.

Manley GA, Yates GK, Köppl C, Johnstone BM (1990) Peripheral auditory processing in the bobtail lizard Tiliqua rugosa. IV. Phase locking of auditory-nerve fibers. J Comp Physiol [A] 167:129-138.

Manley GA, Köppl C, Yates GK (1997) Activity of primary auditory neurones in the cochlear ganglion of the Emu Dromaius novaehollandiae I: spontaneous discharge, frequency tuning and phase locking. J Acoust Soc Am 101:1560-1573.

Oertel D (1985) Use of brain slices in the study of the auditory system: spatial and temporal summation of synaptic inputs in cells in the anteroventral cochlear nucleus of the mouse. J Acoust Soc Am 78:328-333.

Palmer AR, Russell IJ (1986) Phase-locking in the cochlear nerve of the guinea-pig and its relation to the receptor potential of inner hair-cells. Hear Res 24:1-15.

Raman IM, Trussell LO (1992) The kinetics of the response to glutamate and kainate in neurons of the avian cochlear nucleus. Neuron 9:173-186.

Rhode WS, Greenberg S (1992) Physiology of the cochlear nuclei. In: The mammalian auditory pathway: neurophysiology (Popper AN, Fay RR, eds), pp 94-152. New York: Springer.

Rose C, Weiss TF (1988) Frequency dependence of synchronization of cochlear nerve fibers in the alligator lizard: evidence for a cochlear origin of timing and non-timing neural pathways. Hear Res 33:151-166.

Ruggero MA (1992) Physiology and coding of sound in the auditory nerve. In: The mammalian auditory pathway: neurophysiology (Popper AN, Fay RR, eds), pp 34-93. New York: Springer.

Sachs MB, Young ED, Lewis RH (1974) Discharge patterns of single fibers in the pigeon auditory nerve. Brain Res 70:431-447.

Sachs MB, Woolf NK, Sinnott JM (1980) Response properties of neurons in the avian auditory system: comparisons with mammalian homologues and consideration of the neural encoding of complex stimuli. In: Comparative studies of hearing in vertebrates (Popper AN, Fay RR, eds), pp 323-353. Berlin: Springer.

Salvi RJ, Saunders SS, Powers NL, Boettcher FA (1992) Discharge patterns of cochlear ganglion neurons in the chicken. J Comp Physiol [A] 170:227-241.

Smith PH, Joris PX, Yin TCT (1993) Projections of physiologically characterized spherical bushy cell axons from the cochlear nucleus of the cat: evidence for delay lines to the medial superior olive. J Comp Neurol 331:245-260.

Smolders JWT, Klinke R (1986) Synchronized responses of primary auditory fiber-populations in Caiman crocodilus (L.) to single tones and clicks. Hear Res 24:89-103.

Sullivan WE, Konishi M (1984) Segregation of stimulus phase and intensity coding in the cochlear nucleus of the barn owl. J Neurosci 4:1787-1799.

Surlykke A, Larsen ON, Michelsen A (1988) Temporal coding in the auditory receptor of the moth ear. J Comp Physiol [A] 162:367-374.

Taniguchi K, Ogawa H (1987) Spectral analysis of instantaneous frequency responses to sinusoidal stimulation in cutaneous mechanoreceptor afferent units of frogs. Jpn J Physiol 37:1031-1049.

Teich MC, Khanna SM, Guiney PC (1993) Spectral characteristics and synchrony in primary auditory-nerve fibers in response to pure-tone acoustic stimuli. J Stat Phys 70:257-279.

Warchol ME, Dallos P (1990) Neural coding in the chick cochlear nucleus. J Comp Physiol [A] 166:721-734.

Weiss TF, Rose C (1988a) A comparison of synchronization filters in different auditory receptor organs. Hear Res 33:175-180.

Weiss TF, Rose C (1988b) Stages of degradation of timing information in the cochlea: a comparison of hair-cell and nerve-fiber responses in the alligator lizard. Hear Res 33:167-174.

Wubbels RJ (1992) Afferent response of a head canal neuromast of the ruff (Acerina cernua) lateral line. Comp Biochem Physiol [A] 102A: $19-26$. 